\title{
Influences of CYP2D6*10 polymorphisms on the pharmacokinetics of iloperidone and its metabolites in Chinese patients with schizophrenia: a population pharmacokinetic analysis
}

\author{
Qi PEI ${ }^{1, \#}$, Lu HUANG ${ }^{1, \#}$, Jie HUANG ${ }^{1}$, Jing-kai GU², Yun KUANG ${ }^{1}$, Xiao-cong ZUO ${ }^{1}$, Jun-jie DING ${ }^{3}$, Hong-yi TAN $^{1}$, \\ Cheng-xian GUO ${ }^{1}$, Shi-kun LIU ${ }^{1, *}$, Guo-ping YANG ${ }^{1, *}$ \\ ${ }^{1}$ Center of Clinical Pharmacology and Pharmacy Department, Third Xiangya Hospital, Central South University, Changsha 410013, \\ China; ${ }^{2}$ Drug Metabolism Research Center of Jilin University, Changchun 130012, China; ${ }^{3}$ Children's Hospital of Fudan University, \\ Shanghai 200032, China
}

\begin{abstract}
Aim: Iloperidone is an atypical antipsychotic drug that is mainly metabolized by CYP2D6, CYP3A4, and cytosolic enzymes. Previous studies show that extensive and poor metabolizers of CYP2D6 exhibit different plasma concentrations of iloperidone and its metabolites. The aim of this study was to develop a parent-metabolite population pharmacokinetic (PPK) model to quantify the effects of CYP2D6*10 allele on the pharmacokinetics of iloperidone and its metabolites in Chinese schizophrenia patients.

Methods: Seventy Chinese schizophrenia patients were enrolled, from whom limited blood samples were collected on $\mathrm{d} 15(\mathrm{O})$ and d 28 (0, 4 and $12 \mathrm{~h}$ after drug administration). The plasma concentrations of iloperidone and its metabolites $M_{1}(P-88)$ and $M_{2}(P-95)$ were simultaneously detected using a validated HPLC-MS assay. CYP2D6*10 (rs1065852) genotyping was performed. A PPK model was developed based on data from the patients using the NONMEM software (version 7.2). A one-compartment model with first-order absorption and elimination was used to describe the pharmacokinetic data related to iloperidone and its metabolites.

Results: Patients with the CYP2D6*10 T/T genotype had significantly higher concentrations of iloperidone and $\mathrm{M}_{1}$, and lower concentrations of $\mathrm{M}_{2}$ than the patients with $\mathrm{C} / \mathrm{C}$ or $\mathrm{C} / \mathrm{T}$ genotypes. The CYP2D6*10 genotype affected the elimination constants for transformation of iloperidone to the metabolites $\mathrm{M}_{1}\left(K_{23}\right)$ and $\mathrm{M}_{2}\left(K_{24}\right)$. The $K_{23}$ value of the patients with $\mathrm{T} / \mathrm{T}$ genotype was 1.34-fold as great as that of the patients with $\mathrm{C} / \mathrm{C}$ or $\mathrm{C} / \mathrm{T}$ genotype. The $K_{24}$ value of the patients with $\mathrm{C} / \mathrm{T}$ and $\mathrm{T} / \mathrm{T}$ genotypes was $0.693-$ and 0.492 -fold, respectively, as low as that of the patients with $\mathrm{C} / \mathrm{C}$ genotype.

Conclusion: CYP2D6*10 mutations affect the pharmacokinetics of iloperidone and its metabolites in Chinese schizophrenia patients, suggesting that the clinical doses of iloperidone for patients with CYP2D6*10 mutations need to be optimized.
\end{abstract}

Keywords: schizophrenia; iloperidone; gene polymorphisms; CYP2D6*10; population pharmacokinetics

Acta Pharmacologica Sinica (2016) 37: 1499-1508; doi: 10.1038/aps.2016.96; published online Sep 262016

\section{Introduction}

Iloperidone is an atypical antipsychotic drug that was approved in 2009 by the Food and Drug Administration (FDA) for the acute treatment of schizophrenia in adults with a high 5-hydroxytryptamine $2 \mathrm{a} /$ dopamine $2\left(5-\mathrm{HT}_{2 \mathrm{a}} / \mathrm{D}_{2}\right)$ receptor antagonist ratio, which results in a relatively low risk of extrapyramidal side effects $(\mathrm{EPS})^{[1,2]}$. The therapeutic reference

\footnotetext{
\# These authors contributed equally to this work.

* To whom correspondence should be addressed.

E-mail ygp9880@126.com (Guo-ping YANG); L8618496@126.com (Shi-kun LIU)

Received 2016-02-17 accepted 2016-07-24
}

range of iloperidone is relatively narrow at $5-10 \mathrm{ng} / \mathrm{mL}$ as defined by the therapeutic drug monitoring (TDM) group of the Arbeitsgemeinschaft für Neuropsychopharmakologie und Pharmakopsychiatrie (AGNP) ${ }^{[3]}$.

Iloperidone undergoes extensive pre-systemic elimination and is cleared through multiple metabolic pathways that include $O$-dealkylation, hydroxylation, decarboxylation/ oxidation and reduction ${ }^{[4,5]}$. Two major metabolites of iloperidone $\left(\mathrm{M}_{1}\right.$, also termed P-88 and $\mathrm{M}_{2}$, also termed P-95) have higher plasma concentrations in humans than iloperidone, although the exact fractions of $\mathrm{M}_{1}$ and $\mathrm{M}_{2}$ formation from the parent iloperidone have not yet been identified. $M_{1}$ may contribute to the therapeutic profile of iloperidone because it 
exhibits receptor-binding affinities that are similar to those of the parent compound. Unlike $\mathrm{M}_{1}, \mathrm{M}_{2}$ is unlikely to add to the therapeutic profile of iloperidone due to its low affinity for the 5- $\mathrm{HT}_{2 \mathrm{a}}$ receptor ${ }^{[6]}$. The roles of CYP2D6, CYP3A4, and other enzymes in iloperidone metabolism have been investigated ${ }^{[7]}$. $\mathrm{M}_{2}$ is a hydroxylation metabolite of iloperidone that is produced by CYP2D6. Cytosolic and microsomal enzymes are related to $\mathrm{M}_{1}$. The $\mathrm{O}$-demethylation metabolites are produced by CYP3A4.

The pharmacokinetic parameters of iloperidone and its metabolites $\left(\mathrm{M}_{1}\right.$ and $\left.\mathrm{M}_{2}\right)$ differ between extensive metabolizers (EM) of CYP2D6 and poor metabolizers (PM) of CYP2D6. For example, the iloperidone plasma exposure is higher in PMs than in EMs, and the elimination half-time $\left(t_{1 / 2}\right)$ of iloperidone is $33 \mathrm{~h}$ or longer in PMs ${ }^{[7]}$. Additionally, CYP2D6 polymorphisms $\left({ }^{*} 10,{ }^{*} 5\right)$ affect the pharmacokinetic parameters of other atypical antipsychotic drugs, such as risperidone ${ }^{[8]}$ and aripiprazole ${ }^{[9]}$. The allele frequencies of CYP2D6*10 (rs1065852, allele $\mathrm{C}>\mathrm{T}$ ) mutations are $48 \%-70 \%^{[10]}$ and $30 \%-50 \%^{[11]}$ in Chinese and other Asian populations (eg, Japanese and Korean populations), respectively. However, the effects of the CYP2D 6 ${ }^{*} 10$ (rs1065852) mutation on the pharmacokinetics of iloperidone in clinical practice remain unknown.

Compared to healthy volunteers, it is difficult to perform classic pharmacokinetic studies with rich blood samples from patients due to ethical considerations and the low recruitment rate in clinical practice. Hence, population pharmacokinetics (PPK) is a better choice for pharmacokinetic studies of patients with limited available sampling points. Additionally, PPK analyses help to quantitatively define the degree and influence of covariates on pharmacokinetic parameters. For example, PPK models have been developed for risperidone to investigate the influences of the CYP2D6 genotype and other factors on the pharmacokinetics of risperidone ${ }^{[12-14]}$.

The aims of this study were to develop a parent-metabolite PPK model of iloperidone and its metabolites in Chinese patients with schizophrenia and to identify the extent of the contribution of the CYP2D6*10 (rs1065852) mutation to the variabilities in the PKs of iloperidone and its metabolites to guide clinical dosage optimization.

\section{Materials and methods}

\section{Patients and study design}

Multiple-center clinical trials were conducted at 13 hospitals in China. The study protocol was designed and performed according to the Declaration of Helsinki and the International Conference Harmonization Guidelines for Good Clinical Practice. Informed consent was obtained from all patients enrolled in the study. Eligible patients included male and female patients between 18 and 65 years of age with a diagnosis of schizophrenia or schizoaffective disorder according to the Diagnostic and Statistical Manual of Mental Disorders (DSMIV) classification. Patients were excluded if they had previously exhibited no positive treatment effects with sufficient drug commitment to psychoactive substances, had received clozapine or other depot antipsychotics in the last three months, were pregnant, or had a history of alcohol or drug abuse, epilepsy, tardive dyskinesia or brain disease.

Based on previous studies ${ }^{[7]}$, the patients' doses were titrated from 2 to $12 \mathrm{mg} / \mathrm{d}$ ( $2 \mathrm{mg} / \mathrm{d}$ on d 1, $4 \mathrm{mg} / \mathrm{d}$ on d 2, $8 \mathrm{mg} / \mathrm{d}$ on $\mathrm{d} 3$ and $12 \mathrm{mg} / \mathrm{d}$ on $\mathrm{d} 4$; twice daily dose regimen). The exact dosing scheme for each patient was recorded.

According to the Fanapt ${ }^{\mathrm{TM}}$ (iloperidone tablets) label ${ }^{[15]}$, the recommended target dosage of iloperidone is 12 to $24 \mathrm{mg} / \mathrm{d}$ administered twice daily $(12 \mathrm{mg} / \mathrm{d}, 16 \mathrm{mg} / \mathrm{d}, 20 \mathrm{mg} / \mathrm{d}$ or 24 $\mathrm{mg} / \mathrm{d}$ ). Based on the patient's tolerance to iloperidone, dose adjustments were performed on d 5-14 after administration of the first dose. The fixed dose after the adjustment was taken on d 15-28. Dosing records were implemented according to individually recorded dosing schemes.

\section{Sampling}

Four blood samples were collected, including one on d 15 $\left(C_{15-0}\right.$, taken on the first day of fixed-dosing) and three on d $28\left(C_{28-0}\right.$, taken before drug administration in the morning; $\mathrm{C}_{28-4}$, taken $4 \mathrm{~h}$ after drug administration in the morning; and $\mathrm{C}_{28-12}$, taken $12 \mathrm{~h}$ after drug administration in the morning). An additional 10-mL blood sample was obtained from each patient for CYP2D6*10 genotyping. The plasma concentrations of iloperidone and its metabolites $M_{1}(P-88)$ and $M_{2}$ (P-95) were simultaneously determined using a validated high-performance liquid chromatography-mass spectrometry assay ${ }^{[16,17]}$. The linear ranges were 1-100 and 3-120 ng/mL for iloperidone and its metabolites, respectively. The limits of detection were 1 and $3 \mathrm{ng} / \mathrm{mL}$ for iloperidone and metabolites, respectively. The extraction recovery rates of the method were greater than $90 \%$ without matrix effects.

\section{Genotyping}

Genomic DNA was isolated from peripheral blood leukocytes using a Wizard ${ }^{\circledR}$ Genomic DNA Purification kit (Promega Corporation, Madison, United State of America) with Technical Manual TM050. CYP2D6*10 (rs1065852) genotyping was performed using the gene sequencing method. The following primer set was used: forward primer, 5'-CATTTGGTAGTGAGGCAGGTAT-3'; reverse primer, 5' -CCTTGCCCTACTCTTCCTTG-3’.

\section{Data analysis}

The subjects' data are presented as the mean \pm the standard deviations (SD) or ranges. The concentrations were normalized to the doses (concentration/dose, $C / D$ ). Differences in the $C / D$ ratio and the pharmacokinetic parameters between the different $C Y P 2 D 6^{*} 10$ genotypes were assessed using multiple linear regression and account for the influence of body weight.

\section{Population pharmacokinetic (PPK) modeling}

The data were graphically presented using R (3.0, http:// www.r-project.org). The nonlinear mixed-effects modeling software program NONMEM (7.2, ICON Development Solutions, USA) with PSN (3.7.6 http:/ / psn.sourceforge.net/index. 
php) was used to develop the PPKs of iloperidone and its metabolites with the ADVAN 6 subroutine using a first-order conditional estimation method with an $\eta-\varepsilon$ interaction.

Both one-compartment and two-compartment structural models with first-order absorption models (with and without an absorption lag time) were tested. However, the one-compartment model with first-order adsorption and elimination was finally used for the parameter estimations of iloperidone and its metabolites in the current study due to the limited blood samples in this study, the limited information about the pharmacokinetics of iloperidone, and the large relative standard errors (RSEs, $>50 \%$ ) or condition numbers (>1000) of the other structural models. A schematic diagram of the model of iloperidone and its metabolites is presented in Figure 1. First, the sequential approach was applied to fit the pharmacokinetics of iloperidone and its metabolites, and a combined model of iloperidone and metabolites was then performed in a simultaneous manner based on the results from the sequential modeling. Because the relative molecular masses of $M_{1}(429.4$ $\mathrm{g} / \mathrm{mol})$ and $\mathrm{M}_{2}(429.2 \mathrm{~g} / \mathrm{mol})$ are both very close to that of iloperidone $(427.3 \mathrm{~g} / \mathrm{mol})$, the mass units rather than the molar units were used for convenience. Due to the lack of a conversion fraction for iloperidone to its metabolites $\left(\mathrm{M}_{1}\right.$ and $\left.\mathrm{M}_{2}\right)$, the pharmacokinetic parameters for $\mathrm{M}_{1}\left(K_{23}\right.$, the formation rate constants of $\mathrm{M}_{1}$, and $K_{30}$, the elimination rate constants of $\mathrm{M}_{1}$ ) and for $\mathrm{M}_{2}\left(K_{24}\right.$, the formation rate constants of $\mathrm{M}_{2}$, and $K_{40}$, the elimination rate constants of $\mathrm{M}_{2}$ ) were simultaneously estimated after setting both $V_{3}$ (the volume of the distribution of $\mathrm{M}_{1}$ ) and $V_{4}$ (the volume of the distribution of $\mathrm{M}_{2}$ ) at $10 \mathrm{~L}$. Proportional, additional, and combined proportional and additional error models were evaluated to describe the residual variability.

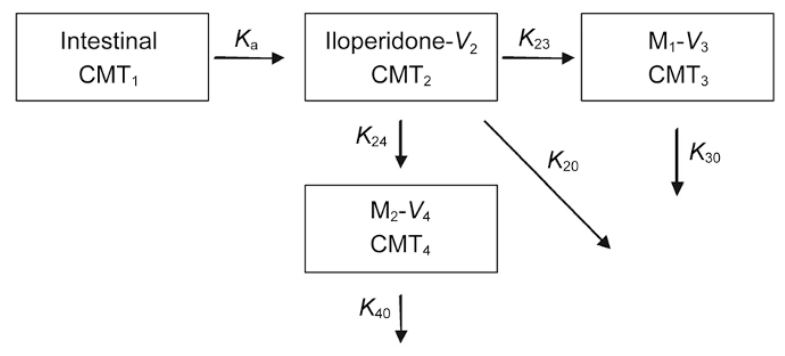

Figure 1. Scheme of the structural model of iloperidone, $M_{1}$ and $M_{2} . K_{a}$ is the absorption constant of iloperidone, $K_{a}$ was set at $2.26 \mathrm{~h}^{-1} ; K_{23}$ and $K_{24}$ represent formation rate constants of $M_{1}$ and $M_{2}$, respectively; $K_{20}$ is the elimination rate of iloperidone by other elimination pathways; $\left(K_{20}+K_{23}+K_{24}\right)$ is the elimination of iloperidone; $K_{23} /\left(K_{20}+K_{23}+K_{24}\right)$ is the conversion fraction rate of iloperidone; $K_{30}$ and $K_{40}$ represent the elimination rate of $\mathrm{M}_{1}$ and $\mathrm{M}_{2}$, respectively; $\mathrm{CMT}_{2}, \mathrm{CMT}_{3}$, and $\mathrm{CMT}_{4}$ represent compartment of iloperidone and metabolites; $V_{2}, V_{3}$, and $V_{4}$ represent the volume of distribution of iloperidone and metabolites.

The covariates in the model construction included demographics, CYP2D6*10 genotype, physiological and biochemical indices obtained before administration, including red blood corpuscle (RBC), total protein, serum creatinine, uric acid and other values. Correlations between any pair of variables were identified through correlation analysis.

Continuous covariates were tested using either the linear [Eq (1)] or power [Eq (2)] equation listed below (using RBCs as an example):

$$
\begin{aligned}
& K_{24}=\operatorname{TV}\left(K_{24}\right)^{*}\left(1+\theta_{1}\left(R B C-R_{B} C_{m}\right)\right)^{*} \exp \left(\eta K_{24}\right) \\
& K_{24}=\operatorname{TV}\left(K_{24}\right)^{*}\left(\operatorname{RBC} / R C_{m}\right)^{\wedge} \theta_{1}^{*} \exp \left(\eta K_{24}\right)
\end{aligned}
$$

where $\operatorname{TV}\left(K_{24}\right)$ is the typical value of the formation rate constant of $\mathrm{M}_{2}\left(K_{24}\right)$ for a patient with the median value for the covariate $\left(\mathrm{RBC}_{\mathrm{m}}\right) . \theta_{1}$ is the estimated influence factor for RBCs. $\eta K_{24}$ is the random between-subject variability.

For categorical covariates, such as the CYP2D6*10 genotype, the effect of the covariates on the $K_{24}$ is expressed as follows:

$$
\begin{aligned}
& \text { IF (genotype.EQ.2) } K_{24}=\theta_{1} * \mathrm{TV}\left(K_{24}\right) \\
& \text { IF (genotype.EQ.3) } K_{24}=\theta_{2} * \operatorname{TV}\left(K_{24}\right)
\end{aligned}
$$

where genotype represents CYP2D6*10. We set CYP2D6*10 $\mathrm{C} / \mathrm{C}$ (ie, the wild-type homozygote), C/T (ie, the heterozygote), and $\mathrm{T} / \mathrm{T}$ (ie, the mutant homozygote) as 1, 2, and 3 , respectively. $\mathrm{TV}\left(K_{24}\right)$ is the typical $K_{24}$ value in patients with the CYP2D6*10 C/C genotype; $K_{24}$ in patients with the CYP2D6*10 C/T genotype was $\theta_{1}^{*} \mathrm{TV}\left(K_{24}\right)$, and this value in patients with the CYP2D ${ }^{*} 10 \mathrm{~T} / \mathrm{T}$ genotype was $\theta_{2}{ }^{*} \mathrm{TV}\left(K_{24}\right)$.

Stepwise forward addition followed by backward elimination processes were used to build the final model. The criteria for addition and elimination were a minimal objective function value (OFV) decrease of $>3.84(P<0.05, \mathrm{df}=1)$ or 5.99 $(P<0.05, \mathrm{df}=2)$ and an OFV increase of $>6.63(P<0.01, \mathrm{df}=1)$ or $9.21(P<0.01, \mathrm{df}=2)$, respectively.

The following goodness-of-fit plots were used to validate the PPK model: the population predicted (PRED) and individual predicted (IPRED) values versus the observed concentrations (DV), and the PRED versus the conditional weighted residuals (CWRES). A nonparametric bootstrap approach and a standard visual predictive check (SVPC) were used to validate the model.

\section{Results}

A total of 70 patients with acute psychotic episodes met the inclusion criteria, and all of these patients completed the study. The CYP2D6*10 alleles (rs1065852) were detected. Eleven patients carried the CYP2D6*10 C/C genotype, 42 patients carried the $\mathrm{C} / \mathrm{T}$ genotype, and 17 patients carried the $\mathrm{T} / \mathrm{T}$ genotype. Four patients $(3 \mathrm{C} / \mathrm{T}$ and $1 \mathrm{~T} / \mathrm{T})$ took iloperidone at a dose of $12 \mathrm{mg} / \mathrm{d}, 12$ patients $(2 \mathrm{C} / \mathrm{C}, 7 \mathrm{C} / \mathrm{T}$ and $3 \mathrm{~T} /$ $\mathrm{T})$ took $16 \mathrm{mg} / \mathrm{d}, 24$ patients $(1 \mathrm{C} / \mathrm{C}, 18 \mathrm{C} / \mathrm{T}$ and $5 \mathrm{~T} / \mathrm{T})$ took $20 \mathrm{mg} / \mathrm{d}$, and 30 patients $(8 \mathrm{C} / \mathrm{C}, 14 \mathrm{C} / \mathrm{T}$ and $8 \mathrm{~T} / \mathrm{T}$ ) took 24 $\mathrm{mg} / \mathrm{d}$ after the dose adjustments. The main patient characteristics are presented in Table 1.

\section{Pharmacokinetic data}

In total, 804 concentration measurements (266 for iloperidone, 268 for $M_{1}$, and 270 for $M_{2}$ ) were implemented in the PK analysis. The $C / D$ ratios of iloperidone and its metabolites differed 
Table 1. Basic characteristic for patients. ${ }^{a}$ Values are expressed as mean \pm SD or mean (ranges) and $n=70$.

\begin{tabular}{|c|c|c|c|c|c|}
\hline \multirow{2}{*}{ Characteristics } & \multirow{2}{*}{$\begin{array}{l}\text { Values }^{\text {a }} \\
(n=70)\end{array}$} & \multicolumn{4}{|c|}{ Dose } \\
\hline & & $12 \mathrm{mg} / \mathrm{d}(n=4)$ & $16 \mathrm{mg} / \mathrm{d}(n=12)$ & $20 \mathrm{mg} / \mathrm{d}(n=24)$ & $24 \mathrm{mg} / \mathrm{d}(n=30)$ \\
\hline Age (year) & $34 \pm 12$ & $38 \pm 4$ & $34 \pm 14$ & $36 \pm 13$ & $31 \pm 10$ \\
\hline Height (m) & $1.64 \pm 0.07$ & $1.63 \pm 0.07$ & $1.64 \pm 0.05$ & $1.62 \pm 0.06$ & $1.66 \pm 0.08$ \\
\hline Weight (kg) & $62.2 \pm 10.5$ & $70.4 \pm 6.6$ & $59.9 \pm 10.2$ & $59.6 \pm 9.4$ & $64.1 \pm 11.3$ \\
\hline BMI & $23.1 \pm 3.5$ & $26.6 \pm 3.1$ & $22.2 \pm 3.6$ & $22.6 \pm 3.5$ & $23.3 \pm 3.45$ \\
\hline \multicolumn{6}{|l|}{ Gender $(n)$} \\
\hline Male & 28 & 2 & 2 & 7 & 17 \\
\hline Female & 42 & 2 & 10 & 17 & 13 \\
\hline \multicolumn{6}{|l|}{ CYP2D6*10 (\%) } \\
\hline $\mathrm{C} / \mathrm{C}$ & $11(15.71 \%)$ & 0 & 2 & 1 & 8 \\
\hline $\mathrm{C} / \mathrm{T}$ & 42 (60.00\%) & 3 & 7 & 18 & 14 \\
\hline $\mathrm{T} / \mathrm{T}$ & $17(24.29 \%)$ & 1 & 3 & 5 & 8 \\
\hline Red blood corpusle $\left(10^{12} / \mathrm{L}\right)$ & \multicolumn{5}{|c|}{$4.5 \pm 0.5(10.8,75)$} \\
\hline Asparate aminotransferase (U/L) & \multicolumn{5}{|c|}{$24.2 \pm 2.0(10.8,75)$} \\
\hline Alanine aminotransferase (U/L) & \multicolumn{5}{|c|}{$22.2 \pm 13.9(5.4,95)$} \\
\hline Total bilirubin (mmol/L) & \multicolumn{5}{|c|}{$13.9 \pm 6.0(6.1,32.8)$} \\
\hline Direct bilirubin (mmol/L) $)^{\#}$ & \multicolumn{5}{|c|}{$3.9 \pm 1.5(1.4,8)$} \\
\hline Blood urea nitrogen (mmol/L) & \multicolumn{5}{|c|}{$4.8 \pm 1.9(1.83,13.8)$} \\
\hline Serum creatinine (mmol/L) & \multicolumn{5}{|c|}{$63.6 \pm 12.0(42,93.4)$} \\
\hline \multicolumn{6}{|c|}{ Number of patients with history of medicine administration (male/female) } \\
\hline
\end{tabular}

\#Values are obtained from 64 patients.

between the $C Y P 2 D 6^{*} 10$ genotypes, as presented in Figure 2. Specifically, the $C / D$ ratio of iloperidone to $M_{1}$ in patients with the CYP2D6*10 T/T genotype was greater than those in patients with the $\mathrm{C} / \mathrm{C}$ and $\mathrm{C} / \mathrm{T}$ genotypes. However, the $\mathrm{C} / \mathrm{D}$ ratio for $\mathrm{M}_{2}$ in patients with the $C Y P 2 D 6^{*} 10 \mathrm{~T} / \mathrm{T}$ genotype was lower than those in patients with the $\mathrm{C} / \mathrm{C}$ and $\mathrm{C} / \mathrm{T}$ genotypes. Statistically significant differences were found in the $C_{28-12} / D$ ratio of iloperidone, the $C_{28-0} / D, C_{28-4} / D$, and $C_{28-12} / D$ ratios of $M_{1}$, and the $C_{15-0} / D$ and $C_{28-0} / D$ ratios of $M_{2}$ between the CYP2D6*10 genotypes.

\section{Population pharmacokinetic (PPK) models}

A one-compartment model with first-order absorption and elimination was sufficient to simultaneously describe the plasma concentrations of iloperidone and its two metabolites. The absorption rate constant $K_{a}$ was estimated to be $2.26 \mathrm{~h}^{-1}$. The estimated parameters included $K_{23}, K_{24}, K_{30}, K_{40}$, the volume distribution of iloperidone $\left(V_{2}\right)$, and the elimination rate of iloperidone by other elimination pathways $\left(K_{20}\right)$. Exponential and proportional models were used to describe inter-subject and residual variabilities, respectively.

In the forward model building step, the CYP2D $6^{*} 10$ and RBC parameters decreased the OFV by more than 3.84 or 5.99 $(P<0.05)$ at each addition. The CYP2D6*10 mutation significantly affected the $K_{23}$ and $K_{24}$. The RBC influenced the volume of iloperidone.

Significant increases in the OFV of more than 6.63 or 9.21
$(P<0.01)$ were produced in the backward elimination step of the model. The CYP2D $6^{*} 10$ genotypes were retained in the final model. The RBC level was excluded in the final model because it resulted in an OFV increase of 3.993, which was less than 6.63. The PPK modeling process and the detailed parameters of the final model are presented in Table 2.

The $K_{23}$ of $\mathrm{M}_{1}$ was affected by the CYP2D6*10 genotypes as illustrated by the following equation: $\left(K_{23}\right)_{\mathrm{i}}=\theta^{*} 0.00451^{*} \exp (\eta \mathrm{i})$. When patients carried the CYP2D $6^{*} 10 \mathrm{C} / \mathrm{C}$ or $\mathrm{C} / \mathrm{T}$ mutations, $\theta=1$, and when patients carried the T/T genotype, $\theta=1.34$. $\eta \mathrm{i}$ was the difference between the estimated value and the typical $K_{23}$ value.

The $K_{24}$ of $\mathrm{M}_{2}$ was affected by the CYP2D $6^{*} 10$ genotypes as illustrated by following equation: $\left(K_{24}\right)_{\mathrm{i}}=\theta^{*} 0.00649^{*} \exp (\eta \mathrm{i})$. When patients carried the CYP2D $6^{*} 10 \mathrm{C} / \mathrm{C}$ mutation, $\theta=1$; when patients carried the CYP2D $6^{*} 10 \mathrm{C} / \mathrm{T}$ mutation, $\theta=0.693$; and when patients carried the $\mathrm{T} / \mathrm{T}$ genotype, $\theta=0.492$. $\eta \mathrm{i}$ was the difference between the estimated value and the typical $K_{24}$ value.

\section{Model validation}

Goodness-of-fit plots for the final pharmacokinetic model are provided in Figure 3. The individual- and populationpredicted plasma concentrations of iloperidone and its metabolites matched the observed plasma concentrations, which indicates that the model describes the data very well. As illustrated in Figure 3, an acceptable range ( -2 to 2 ) was found 


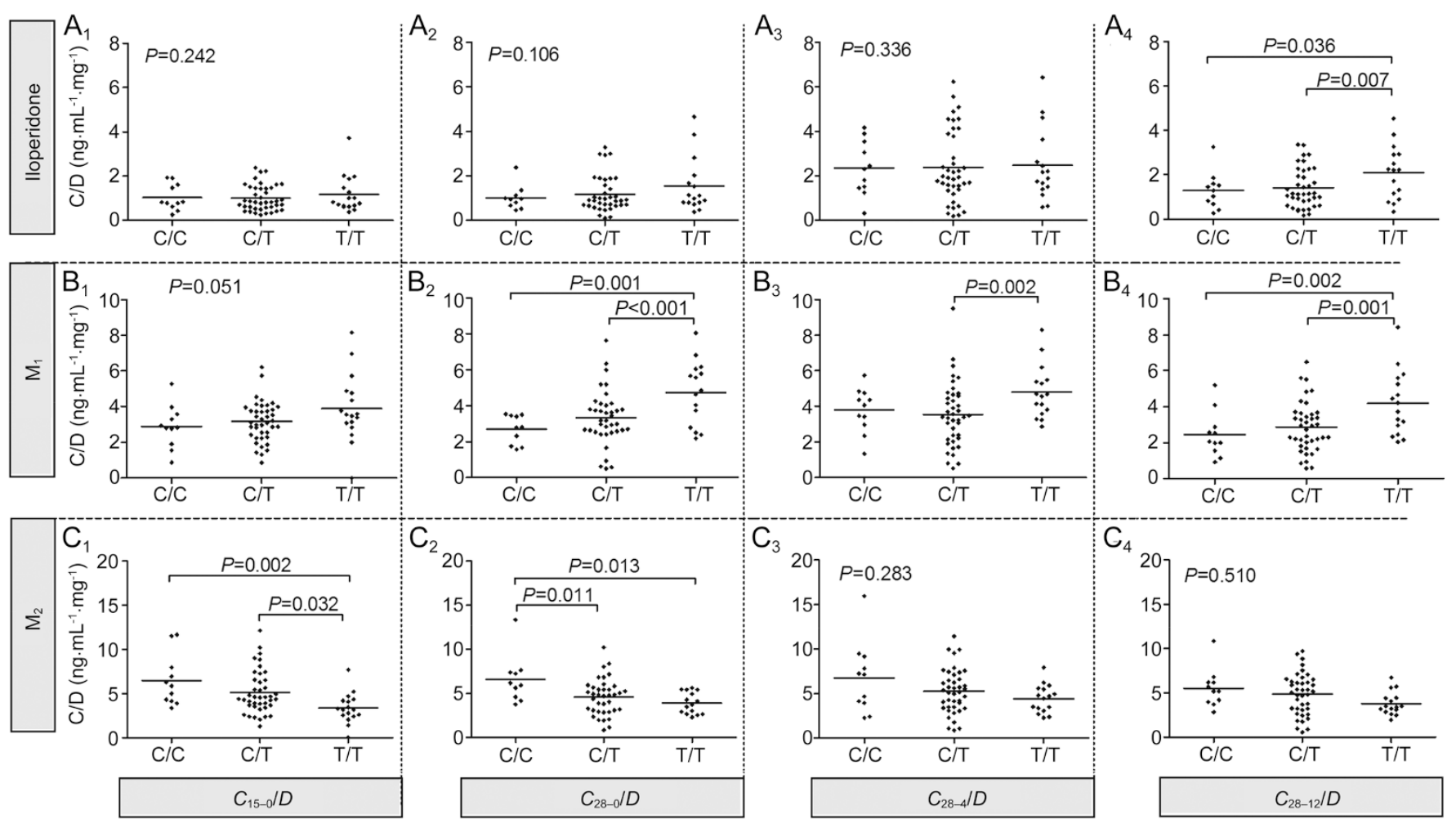

Figure 2. Concentration/Dose ratio of iloperidone, $M_{1}$, and $M_{2}$ separated by CYP2D6*10 genotype. $C / D$ is the concentration/dose ratio; $A$, $B$, and $C$ represent figures for iloperidone, $\mathrm{M}_{1}$, and $\mathrm{M}_{2}$, respectively; $\mathrm{C} / \mathrm{C}, \mathrm{C} / \mathrm{T}$, and $\mathrm{T} / \mathrm{T}$ represent $\mathrm{CYP} 2 \mathrm{D} 6 \star 10$ genotypes. $P$-values are from multiple linear regression (corrected by body weight).

Table 2. Population pharmacokinetic modeling process.

\begin{tabular}{|c|c|c|c|}
\hline № & Model description & OFV & $\Delta \mathrm{OFV}$ \\
\hline \multicolumn{3}{|c|}{ Model building } & $(\mathrm{df}=1, P=0.05,3.84)(\mathrm{df}=2, P=0.05,5.99)$ \\
\hline 1 & 1-Compartment base model & 4568.535 & \\
\hline 3 & Add CYP2D $6 * 10^{1}$ on $K_{23}$ in model 2 & 4537.103 & -10.468 \\
\hline 4 & Add RBC on $V_{2}$ in model 3 & 4531.905 & -5.198 \\
\hline $5^{\#}$ & Remove RBC on $V_{2}$ in model 4 & 4537.103 & -5.198 \\
\hline 6 & Remove CYP2D6*10 ${ }^{1}$ on $K_{23}$ in model 4 & 4547.168 & 15.263 \\
\hline 7 & Remove CYP2D $6 * 10^{2}$ on $K_{24}$ in model 4 & 4540.699 & 8.794 \\
\hline
\end{tabular}

OFV, objective function value; RBC, red blood corpuscle; CYP2D6*10 1 data divided into two groups: CYP2D6*10 (C/C+C/T) vs T/T; CYP2D6*10 ${ }^{2}$ data divided into three groups: CYP2D6*10 C/C vs C/T vs T/T. " Final model.

in which the conditional weighted residuals (CWRES) were randomly distributed around zero, which demonstrates that the CWRES did not reflect any particular systematic trends.

The mean parameter estimates and 95\% CIs from the bootstrap analysis are presented in Table 3. The covariance step was $92.6 \%$ successful. There were no statistically significant differences from the estimates based on the original dataset. The variability estimates from the bootstrap analysis were similar to the estimates from the original data. Figure 4 illus- trates the SVPC of the pharmacokinetic model of iloperidone and its metabolites. The open circles represent the calculated $\mathrm{P}_{\mathrm{i}, \mathrm{j}}$ values obtained from 1000 simulated datasets for each observation versus time .

\section{Influence of CYP2D6*10 on the clearance of iloperidone and the PPK parameters}

The clearance of iloperidone was not markedly affected by the CYP2D $6^{*} 10$ genotypes, but the $K_{23}$ and $K_{24}$ values were notably 

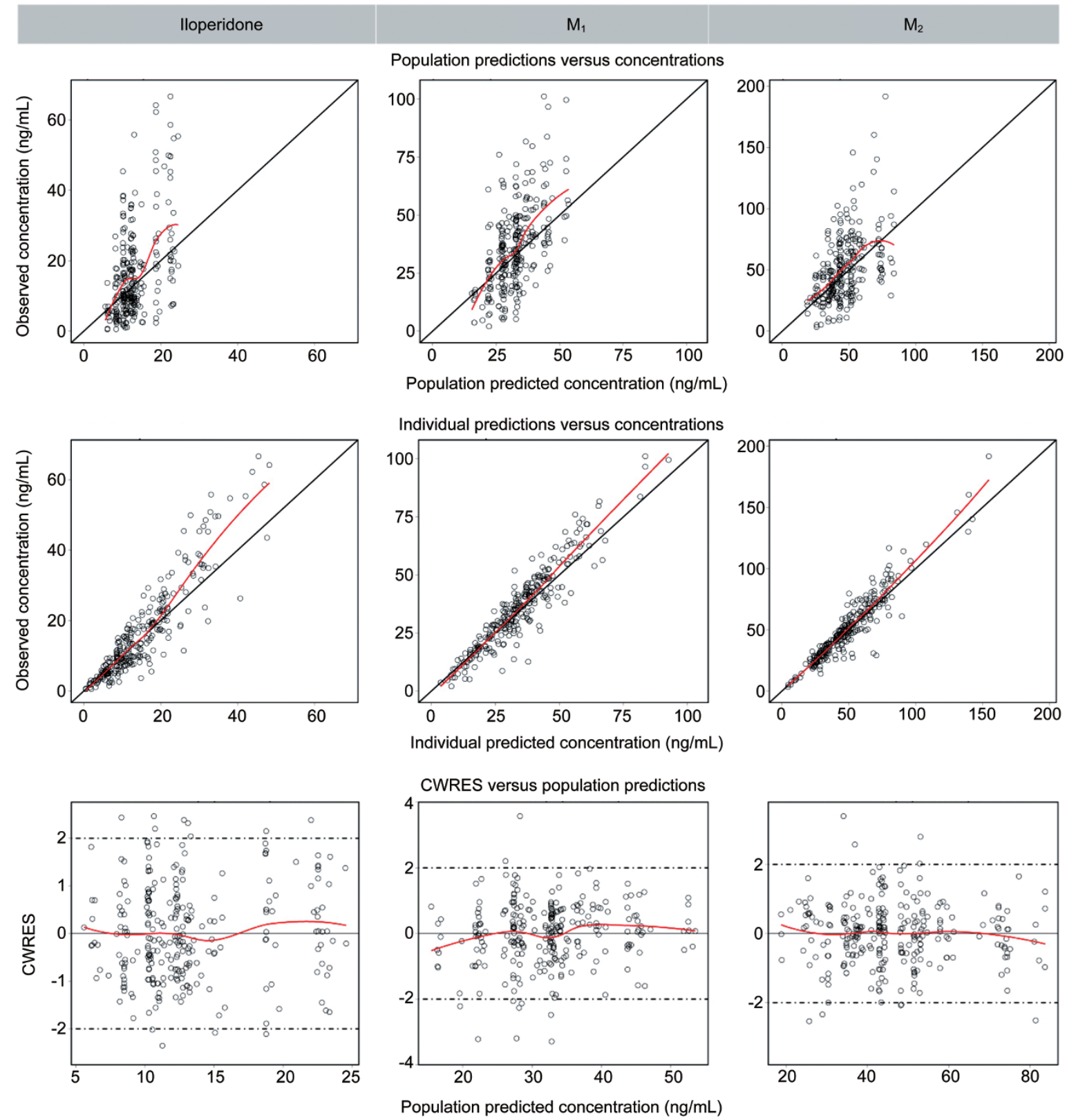

Figure 3. Goodness-of-fit plots for the final pharmacokinetic model of iloperidone, $\mathrm{M}_{1}$, and $\mathrm{M}_{2}$. Population observed versus predicted plasma (upper panel), individual observed versus predicted plasma (middle panel), CWRES (conditional weighted residuals) versus population predicted plasma (lower panel) with line of identity (black line) and regression line (red line).

affected by the $C Y P 2 D 6^{*} 10$ genotypes $(P<0.01$, Figure 5$)$.

\section{Discussion}

In the present study, the genotypic frequencies of CYP2D $6^{*} 10$ $\mathrm{C} / \mathrm{C}, \mathrm{C} / \mathrm{T}$, and $\mathrm{T} / \mathrm{T}$ were found to be $0.16,0.6$, and 0.24 , respectively, in Chinese patients with schizophrenia. These allele frequencies are similar to those that have been reported in other Asian populations but higher than those reported for Caucasians and African Americans, in whom the frequency of the CYP2D $6^{*} 10$ allele was found to be $2 \%-5 \%\left[{ }^{[9,10]}\right.$.

In Japanese psychiatric patients, the number of CYP2D $6^{*} 10$ alleles has been found to significantly affect dose-corrected plasma risperidone levels ${ }^{[18]}$. Several PPK models have been developed for risperidone to study the influence of CYP2D $6^{*} 10$ genotype on the pharmacokinetics of risperidone ${ }^{[12-14,21,22]}$. In the current study, the influences of $C Y P 2 D 6^{*} 10$ alleles on the dose-corrected plasma concentrations of iloperidone and its metabolites were evaluated in Chinese patients with schizophrenia. Although some differences were observed between the significances of $M_{1}$ and $M_{2}$ at different time points (particularly in the $C_{28-4} / D$ and $C_{28-12} / D$ ratio), which may have been due to the limited sample size, patients with the 
Table 3. Population pharmacokinetic parameters of iloperidone and metabolites in Chinese patients with schizophrenia and bootstrap validation.

\begin{tabular}{|c|c|c|c|c|}
\hline Parameters & Estimate & RSE (\%) & Median & $95 \% \mathrm{Cl}$ \\
\hline$K_{a}\left(h^{-1}\right)$ & 2.26 & FIX & & \\
\hline$K_{20}\left(h^{-1}\right)$ & 0.067 & 13.3 & 0.068 & $0.051-0.082$ \\
\hline$K_{30}\left(h^{-1}\right)$ & 0.160 & 30.6 & 0.161 & $0.101-0.223$ \\
\hline$K_{40}\left(h^{-1}\right)$ & 0.106 & 29.6 & 0.108 & $0.057-0.173$ \\
\hline$V_{4}(\mathrm{~L})$ & 10 & FIX & & \\
\hline$K_{23}\left(h^{-1}\right)$ & 0.00451 & 27.7 & 0.00459 & $0.00276-0.00627$ \\
\hline$K_{24}\left(h^{-1}\right)$ & 0.00649 & 31.1 & 0.00664 & $0.00292-0.0113$ \\
\hline CYP2D6*10 C/T on $K_{24}$ & 0.693 & 18.9 & 0.699 & $0.518-0.919$ \\
\hline CYP2D6*10 T/T on $K_{24}$ & 0.492 & 24.2 & 0.488 & $0.362-0.652$ \\
\hline$V_{2}(\%)$ & 35.8 & 19 & 35.0 & $25.6-45.6$ \\
\hline$K_{23}(\%)$ & 19.6 & 26 & 19.3 & $8.5-28.1$ \\
\hline$K_{24}(\%)$ & 40.9 & 13 & 39.2 & $30.5-48.2$ \\
\hline \multicolumn{5}{|l|}{ Inter-occasion variability } \\
\hline$K_{20}$ & 27.3 & 10 & 26.9 & $17.1-37.5$ \\
\hline \multicolumn{5}{|l|}{ Residual variability } \\
\hline $\mathrm{CV}^{1}(\%)$ & 37.7 & 15 & 37.8 & $32.8-42.6$ \\
\hline $\mathrm{CV}^{2}(\%)$ & 23.6 & 9 & 23.5 & $19.1-29.0$ \\
\hline $\mathrm{CV}^{3}(\%)$ & 22.1 & 7 & 22.3 & $17.2-26.5$ \\
\hline
\end{tabular}

RSE, relative standard error; CV, proportional residual variance; $\mathrm{Cl}$, confidence interval; ${ }^{1}$ for iloperidone; ${ }^{2}$ for metabolite $\mathrm{M}_{1} ;{ }^{3}$ for metabolite $\mathrm{M}_{2}$.

CYP2D6*10 T/T genotype were generally observed to exhibit a higher steady-state plasma concentration of $\mathrm{M}_{1}$ and a lower steady-state plasma concentration of $\mathrm{M}_{2}$ relative to the other genotype groups at all of the time points. Therefore, the CYP2D ${ }^{*} 10$ genotypes affected the steady-state concentrations of iloperidone and its metabolites, which is consistent with the fact that $\mathrm{M}_{2}$ is primarily formed by CYP2D $6^{[19,20]}$.

In this study, we developed the first parent-metabolite PPK model to evaluate the influence of the CYP2D $6^{*} 10$ genotype on iloperidone and its metabolites in Chinese patients with schizophrenia. Only limited samples were collected, particularly in the absorption phase, during clinical practice. A one-compartment model with first-order adsorption and elimination was able to simultaneously describe the clinical observations of the concentrations of iloperidone and its two metabolites. The absorption rate constant $K_{\mathrm{a}}$ was estimated to be $2.26 \mathrm{~h}^{-1}$ with a relatively large RSE. However, to the best of our knowledge, no $K_{\mathrm{a}}$ value has yet been reported in the literature due to limited research on iloperidone pharmacokinetics. A drug concentration-time curve from the only available pharmacokinetic study of iloperidone in Chinese healthy volunteers ${ }^{[23]}$ was generated using the Getdata Graph Digitizer (http:/ / www.getdata-graph-digitizer.com) and further analyzed using a two-compartment model. This model produced a $K_{\mathrm{a}}$ of $1.68 \mathrm{~h}^{-1}$, which is comparable to the $K_{\mathrm{a}}$ value $\left(2.26 \mathrm{~h}^{-1}\right)$ estimated in our study.

Iloperidone elimination was found to be significantly affected by the CYP2D 6 10 variants. Iloperidone was transformed less into metabolite $\mathrm{M}_{2}$ and more into metabolite $\mathrm{M}_{1}$ in patients with the CYP2D6*10 T alleles. The box plot in Figure 5 illustrates the influence of $C Y P 2 D 6^{*} 10$ on the clearance of iloperidone and the PPK parameters $\left(K_{23}\right.$ and $\left.K_{24}\right)$. Although the clearance of iloperidone was not significantly affected by the different CYP2D6 $6^{*} 10$ genotypes, the $K_{23}$ and $K_{24}$ values were notably affected by the CYP2D $6^{*} 10$ genotype $(P<0.01)$. The concentrations of the $M_{1}$ metabolite were higher in patients with the CYP2D6*10 T/T genotype than in patients with the CYP2D ${ }^{*} 10 \mathrm{C} / \mathrm{C}$ or $\mathrm{C} / \mathrm{T}$ genotypes, which indicated that iloperidone is primarily metabolized to $M_{1}$ in patients with the CYP2D6*10 T/T genotype. $\mathrm{M}_{1}$ may contribute to an enhanced clinical profile and tolerability of iloperidone based on observations from a preclinical pharmacokinetic study ${ }^{[6]}$. Clinically, compared to metabolite $\mathrm{M}_{2}$, metabolite $\mathrm{M}_{1}$ is more active in terms of binding to the dopamine and serotonin receptors through the blood brain barrier. Therefore, it will be useful to apply genotype-based dosing as more therapeutic information about $\mathrm{M}_{1}$ becomes available.

The influence of low percentages below the quantification 


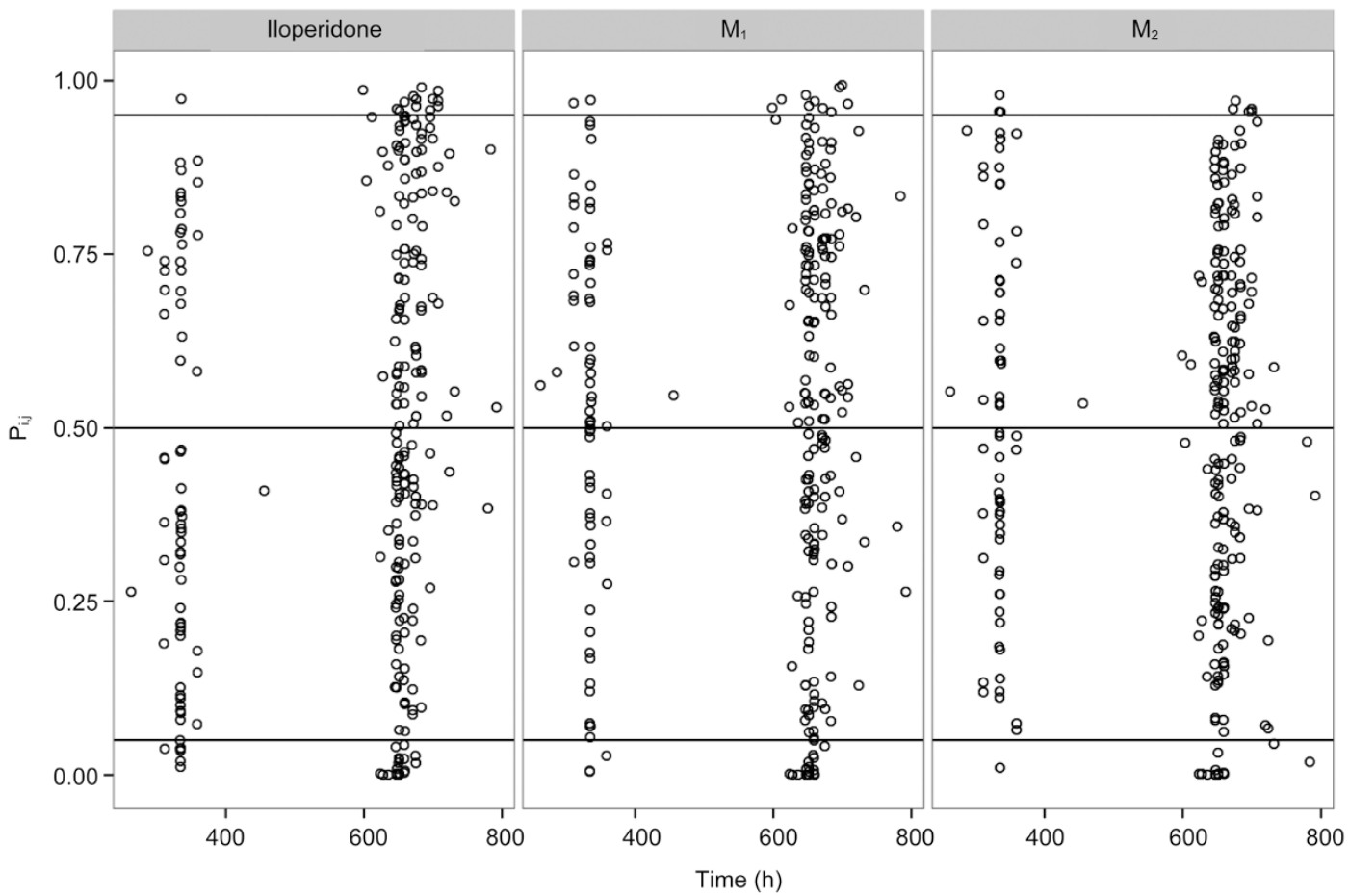

Figure 4. SVPC (Standard Visual Predictive Check) plots for iloperidone, $\mathrm{M}_{1}$, and $\mathrm{M}_{2}$. Open circles, calculated $\mathrm{P}_{\mathrm{i}, \mathrm{j}}$ for each observation versus time; dashed line, model-predicted 5th, 50th, and 95th percentiles of model-predicted $\mathrm{P}_{\mathrm{i}, \mathrm{j}}$ (from bottom to top). $\mathrm{P}_{\mathrm{i}, \mathrm{j}}$, percentile of each observation of each participant in the marginal distribution of model-simulated endpoints.

A

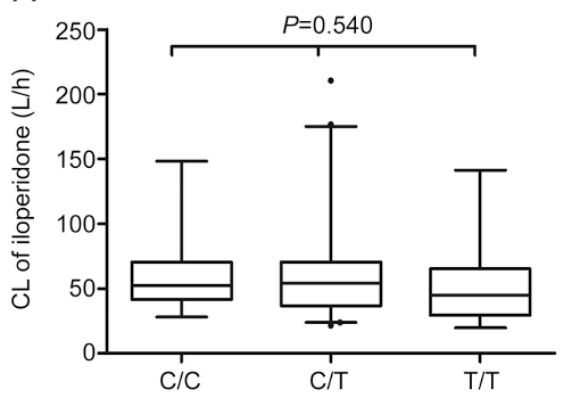

B

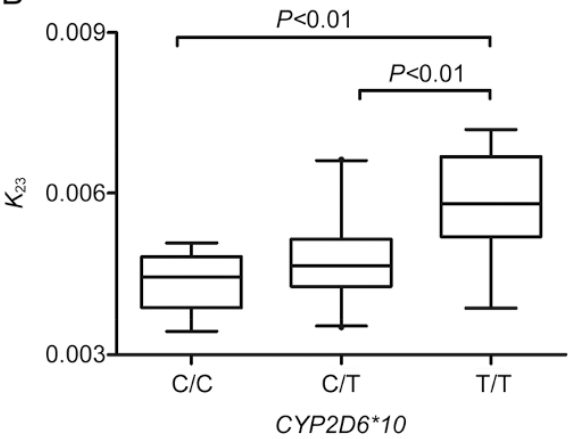

C

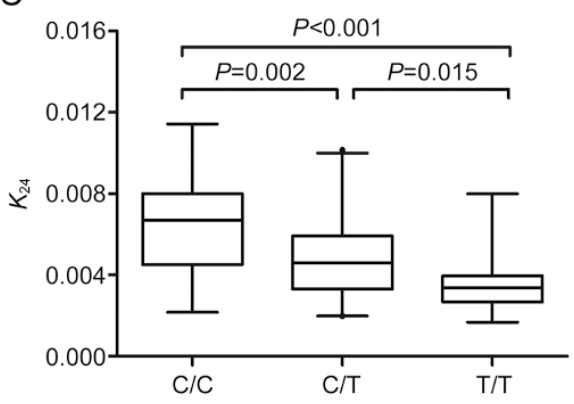

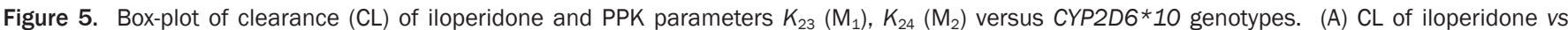

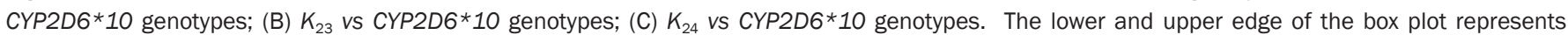
the first quartile and the third quartile. The whisker is 5 to 95 percentile. Solid circles indicate outliers.

limit (BQL, ie, $\leq 10 \%$ ) has been demonstrated to be negligible in one-compartment models ${ }^{[25]}$. In the current study, the percentages of BQL data for iloperidone, $\mathrm{M}_{1}$, and $\mathrm{M}_{2}$ were $1.48 \%$ ( 4 out of 270$), 0.74 \%$ ( 2 out of 270 ), and 0 ( 0 out of 270 ), respectively. Therefore, the results of the model were likely not significantly influenced by exclusion of the BQL data from the analysis.

However, the present study has some limitations. The sparse sampling design, limited number of blood samples in the absorption phase, and relatively low number of patients may have affected the estimations of the inter-individual vari- abilities of the parameters. In the current study, the RBC value was excluded from the final model, although its influence on the distribution of iloperidone may not be negligible because the number of RBCs can affect the hematocrit value (ie, the primary determinant of the blood viscosity) and hence the drug plasma protein-binding rate ${ }^{[24]}$.

In our preliminary exercise, the two-compartment model provided the best fit to the mean concentration-time data for iloperidone in healthy Chinese volunteers ${ }^{[23]}$. In contrast, a one-compartment model better described the concentrationtime profiles of iloperidone and its two metabolites in Chinese 
schizophrenia patients in the present study. If iloperidone in patients also exhibits the characteristics of a two-compartment model, the use of a one-compartment model to fit the data from patients in the present study would have a certain influence on the parameter estimates.

There is a lack of information in the literature related to the metabolism of iloperidone, including the exact fractions of the conversion of iloperidone to its two metabolites. Specifically, the pharmacokinetic data for iloperidone and metabolites have not been verified in Chinese patients. The details of other enzymes and other CYP2D6 alleles (CYP2D $\left.{ }^{*} 2,{ }^{*} 17\right)$ that may play roles in the metabolism of iloperidone are not available for the current study. There are no data regarding iloperidone and its metabolites from patients who are co-medicated with CYP2D6 inhibitors. Therefore, further studies with comprehensive protocols should be performed.

In conclusion, this is the first study to identify the effects of CYP2D ${ }^{*} 10$ variants on the PKs of iloperidone and its metabolites in Chinese patients with schizophrenia using a parentmetabolite PPK analysis. Dosages may need to be optimized for patients with CYP2D $6^{*} 10$ mutations, particularly those with the CYP2D6*10 T/T genotype.

\section{Acknowledgements}

The authors wish to thank the investigators from the 13 hospitals led by the 6th Hospital of Peking University in China for collecting the samples and the data. The authors would also like to thank the co-investigators from the Jilin University Drug Metabolism Research Center for data analysis. This study was supported by grants from the International Science \& Technology Cooperation Program of China (No 2014DFA30900), the National Key Clinical Specialist Construction Programs of China, the National Natural Science Foundation of China (No 81302851, 81373476, 81301924), the State Scholarship Fund (№ 201308430123), the Health Department Foundation of Hunan Province (№ 132013-028) and the Program for Science and Technology Research of Hunan Province (No 2012WK3044).

\section{Author contribution}

Guo-ping YANG, Shi-kun LIU, and Qi PEI conceived and designed the experiments; Jing-kai GU, and Hong-yi TAN analyzed the plasma concentrations. Cheng-xian GUO provided the sequencing data. Lu HUANG, Jie HUANG, and Yun KUANG analyzed the data. Qi PEI, Jun-jie DING, and Xiao-cong ZUO constructed the model. Lu HUANG, Qi PEI, and Guo-ping YANG wrote the paper. Guo-ping YANG, Qi PEI, Lu HUANG, Jie HUANG, Shi-kun LIU, and Xiao-cong $\mathrm{ZUO}$ reviewed and edited the manuscript. All authors have read and approved the manuscript.

\section{References}

1 Kalkman HO, Feuerbach D, Lötscher E, Schoeffter P. Functional characterization of the novel antipsychotic iloperidone at human $D_{2}, D_{3}$, alpha $_{2 \mathrm{C}}, 5-\mathrm{HT}_{6}$, and 5- $\mathrm{HT}_{1 \mathrm{~A}}$ receptors. Life Sci 2003; 73: 115-59.

2 Kalkman HO, Subramanian N, Hoyer D. Extended radioligand bind- ing profile of iloperidone: a broad spectrum dopamine/serotonin/ norepinephrine receptor antagonist for the management of psychotic disorders. Neuropsychopharmacology 2001; 25: 904-14.

3 Hiemke C, Baumann P, Bergemann N, Conca A, Dietmaier O, Egberts K, et al. AGNP consensus guidelines for therapeutic drug monitoring in psychiatry: update 2011. Phar 2011. Pharmacopsychiatry 2011; 44: 195-235.

4 Jain KK. An assessment of iloperidone for the treatment of schizophrenia. Expert Opin Investig Drugs 2000; 9: 2935-43.

5 Sainati SM, Hubbard JW, Chi E, Grasing K, Brecher MB. Safety, tolerability, and effect of food on the pharmacokinetics of iloperidone (HP 873), a potential atypical antipsychotic. J Clin Pharmacol 1995; 35: 712-20.

6 Subramanian N, Kalkman HO. Receptor profile of P88-8991 and P9512113, metabolites of the novel antipsychotic iloperidone. Prog Neuropsychopharmacol Biol Psychiatry 2002; 26: 553-60.

7 US Food and Drug Administration. Iloperidone, Approval History, NDA022192, review: (accessed September 2009).

8 Kang RH, Jung SM, Kim KA, Lee DK, Cho HK, Jung BJ, et al. Effects of CYP2D6 and CYP3A5 genotypes on the plasma concentrations of risperidone and 9-hydroxyrisperidone in Korean schizophrenic patients. J Clin Psychopharmacol 2009; 29: 27-7.

9 Kubo M, Koue T, Maune H, Fukuda T, Azuma J. Pharmacokinetics of aripiprazole, a new antipsychotic, following oral dosing in healthy adult Japanese volunteers: influence of CYP2D6 polymorphism. Drug Metab Pharmacokinet 2007; 22: 358-66.

10 Cai WM, Chen B, Zhang WX. Frequency of CYP2D6*10 and *14 alleles and their influence on the metabolic activity of CYP2D 6 in a healthy Chinese population. Clin Pharmacol Ther 2007; 81: 95-8.

11 Bradford LD. CYP2D6 allele frequency in European Caucasians, Asians, Africans and their descendants. Pharmacogenomics 2002; 3: 229-43.

12 Sherwin CM, Saldaña SN, Bies RR, Aman MG, Vinks AA. Population pharmacokinetic modeling of risperidone and 9-hydroxyrisperidone to estimate CYP2D6 subpopulations in children and adolescents. Ther Drug Monit 2012; 34: 535-44.

13 Yoo HD Cho HY, Lee SN, Yoon H, Lee YB. Population pharmacokinetic analysis of risperidone and 9-hydroxyrisperidone with genetic polymorphisms of CYP2D6 and ABCB1. J Pharmacokinet Pharmacodyn 2012; 39: 329-41.

14 Locatelli I, Kastelic M, Koprivsek J, Kores-Plesnicar B, Mrhar A, Dolzan $\mathrm{V}$, et al. A population pharmacokinetic evaluation of the influence of CYP2D6 genotype on risperidone metabolism in patients with acute episode of schizophrenia. Eur J Pharm Sci 2010 41: 289-98.

15 FANAPT label. http://www.accessdata.fda.gov/drugsatfda_docs/ label/2009/022192lbl.pdf

16 Parekh JM, Sanyal M, Yadav M, Shrivastav PS. Stable-isotope dilution LC-MS/MS assay for determination of iloperidone and its two major metabolites, P-88 and P-95, in human plasma: application to a bioequivalence study. Bioanalysis 2013; 5: 669-86.

17 Mutlib AE, Strupczewski JT. Picogram determination of iloperidone in human plasma by solid-phase extraction and by high-performance liquid chromatography-selected-ion monitoring electrospray mass spectrometry. J Chromatogr B Biomed Appl 1995; 669: 237-46.

18 Suzuki Y, Fukui N, Tsuneyama N, Watanabe J, Ono S, Sugai T, et al. Effect of the cytochrome P450 2D6*10 allele on risperidone metabolism in Japanese psychiatric patients. Hum Psychopharmacol 2012; 27: 43-6.

19 Rado JT, Janicak PG. Long-term efficacy and safety of iloperidone: an update. Neuropsychiatr Dis Treat 2014; 10: 409-15.

20 Caccia S, Pasina L, Nobili A. New atypical antipsychotics for schizo- 
phrenia: iloperidone. Drug Des Devel Ther 2010; 4: 33-48.

21 Uchida H, Mamo DC, Pollock BG, Suzuki T, Tsunoda K, Watanabe K, et al. Predicting plasma concentration of risperidone associated with dosage change: a population pharmacokinetic study. Ther Drug Monit 2012; 34: 182-7.

22 Thyssen A, Vermeulen A, Fuseau E, Fabre MA, Mannaert E. Population pharmacokinetics of oral risperidone in children, adolescents and adults with psychiatric disorders. Clin Pharmacokinet 2010; 49: 465-78.

23 Jia M, Li J, He X, Liu M, Zhou Y, Fan Y, et al. Simultaneous determina- tion of iloperidone and its two active metabolites in human plasma by liquid chromatography-tandem mass spectrometry: application to a pharmacokinetic study. J Chromatogr B Analyt Technol Biomed Life Sci 2013; 928: 52-7.

24 Pirofsky B. The determination of blood viscosity in man by a method based on Poiseuille's law. J Clin Invest 1953; 32: 292-8.

25 Xu XS, Dunne A, Kimko H, Nandy P, Vermeulen A. Impact of low percentage of data below the quantification limit on parameter estimates of pharmacokinetic models. J Pharmacokinet Pharmacodyn 2011; 48: 423-32. 